\title{
ARBORIZAÇÃO DA AVENIDA DEPUTADO ULISSES GUIMARÃES, BAIRRO PROMORAR, ZONA SUL DE TERESINA - PI
}

\author{
AFFORESTATION OF DEPUTADO ULYSSES GUIMARÃES AVENUE, \\ PROMORAR NEIGHBORHOOD, SOUTH ZONE OF TERESINA-PI
}

\author{
Ranyellson Pires Barbosa1; Mirya Grazielle Torres Portela²; Roselis Ribeiro Barbosa Machado3; \\ Alane Sousa Sá ${ }^{4}$
}

\section{RESUMO}

A arborização urbana pelos benefícios que produz deveria ser considerada como um dos elementos naturais mais importantes que compõem o ecossistema das cidades e imprescindível no planejamento urbano. Objetivou-se com esse estudo quantificar e qualificar a arborização da Avenida Deputado Ulisses Guimarães, no bairro Promorar, zona sul de Teresina-PI. Foram avaliados, porte, fitossanidade, localização e área de crescimento das árvores. Foram registrados 284 indivíduos, pertencentes a 23 espécies, distribuídas em 14 famílias, sendo $52,17 \%$ do total das espécies nativas. As espécies que apresentaram maior número de indivíduos foram o Azadirachta indica A. Juss. (nim), Handroanthus chrysotrichus (Mart. ex DC.) Mattos (ipê-amarelo), Mangifera indica L. (mangueira), Terminalia catappa L. (amêndoa), com 33,00, 14,00, 13,00 e 12,00\%, respectivamente, do total, indicando muitos indivíduos representados por poucas espécies. Observou-se que os indivíduos amostrados estavam localizados, em sua maioria, na parte central do canteiro. Embora a arborização tenha apresentando boas condições fitossanitárias, e ausência de conflito com a fiação necessita-se de atenção para o percentual de espécies exóticas, a presença de frutíferas e aos conflitos do sistema radicular com o piso, dando enfoque ao planejamento da arborização da avenida, aliada aos padrões indicados na literatura.

Palavras-chave: Espécies vegetais; Vias públicas; Diagnóstico.

\section{ABSTRACT}

The urban forestry for the benefits it produces should be considered as one of the most important natural elements that composes the ecosystem of the cities and indispensable in urban planning. The objective of this study was to quantify and qualify the afforestation of Deputado Ulysses Guimarães Avenue in Promorar neighborhood, south of Teresina, PI. The parameters evaluated were size, phytosanitary condition, location and tree growth area. There were recorded 284 individuals, in 22 species and 14 families, with $52.17 \%$ of native species and $47.83 \%$ exotic. The species with greater number of registration were Azadirachta indica A. Juss. (neem), Handroanthus chrysotrichus (Mart. ex DC.) Mattos (yellow ipe), Mangifera indica L. (mango), Terminalia catappa L. (almond) with 33, 14, 13 and $12 \%$, respectively, of the total, indicating many individuals represented by few species. It was observed that individuals were located mostly in the central part of the site. Although afforestation has presented good phytosanitary conditions and absence of conflict with the wiring, it needs attention to the percentage of exotic species, the presence of fruitful trees and conflicts of the root system to the floor, giving focus to the planning of the avenue of trees, coupled with the standards indicated in the literature.

Keywords: Plant species; Public Roads; Diagnostics.

Recebido em 31.08.2015 e aceito em 10.11.2015

1 Engenheiro Agrônomo, Msc. em Fitotecnia, Universidade Federal do Piaú- UFPI, Campus Profa Cinobelina Elvas, Bom Jesus-PI. E-mail: ranyellson_agronomo@hotmail.com

2 Engenheira Agrônoma, Gestora Ambiental, Msc em Agronomia, Universidade Federal do Piauí- UFPI, Campus Petrônio Portela, Teresina-PI. E-mail: mgagronoma@yahoo.com.br

3 Bióloga, Doutora em Geografia, Departamento de Ciências Biológicas da Universidade Estadual do Piauí- UESPI, Campus Torquato Neto, Teresina-PI. E-mail: roselis.machado@ig.com.br

4 Bióloga, Esp. em Gestão Ambiental da Universidade Estadual do Piauí- UESPI, Campus Torquato Neto, Teresina-PI. E-mail: alanesousa@gmail.com 


\section{INTRODUÇÃO}

Há muito tempo o homem vem trocando o meio rural pelo urbano e o crescimento desordenado de grande parte das cidades brasileiras e as ocupações irregulares do solo têm dificultado os planejamentos adequados que viabilizem uma conexão da área construída com a vegetada. A arborização urbana pelos benefícios que produz, deveria ser considerada como um dos elementos naturais mais importantes que compõem 0 ecossistema das cidades e imprescindível no planejamento urbano (OLIVEIRA; SANCHES; DE MUSIS, 2013).

Para Silva et al. (2008), a paisagem urbana deve integrar o homem com o meio ambiente e satisfazer às suas necessidades. No entanto, em decorrência do crescimento muitas vezes inadequado das cidades, o meio ambiente urbano vem sofrendo diversas modificações, que contribuem para a insatisfação da população.

Muitos aspectos positivos para o bem-estar humano estão relacionados às árvores, pois as mesmas também atuam nos fatores psicológicos e sociais. Causa influência no estado de ânimo das pessoas e cria um ambiente agradável para a prática de exercícios físicos, reduzindo ruídos e melhorando a estética dos locais onde se encontram (CRUZ; BEVILAQUA; ARRUDA, 2012)

Londe e Mendes (2014) destacam que as áreas com arborização além de atribuir melhorias ao meio ambiente e ao equilíbrio ambiental podem contribuir para o desenvolvimento social e trazer benefícios a qualidade de vida da população ao promoverem condições de aproximação do homem com o meio natural.

Nesse sentido, Basso e Corrêa (2014) enfatizam que a arborização cumpre diversas funções no sistema de espaços livres de uma cidade, das quais se destacam as melhorias no microclima, diminuição de poluição do ar, sonora e visual, abrigo para a fauna que vive nas cidades.

A escolha adequada de qual espécie utilizar e onde utilizar significa o sucesso do planejamento e a diminuição de gastos com tratos culturais e manutenção, sendo necessários estudos para a elaboração de planejamento, projeto e gestão urbana que envolva a arborização (KRAMER; KRUPEK, 2012; BASSO; CORRÊA, 2014). Nesse sentido, o planejamento é primordial para que se tenha sucesso na arborização de ruas e avenidas, visto que, plantas com porte adequado acarretam em diminuição de gastos para sua manutenção, principalmente quando se trata de podas. Salienta-se ainda que plantas com suas estaturas adequadas e distanciadas corretamente diminuem os conflitos entre suas copas e entre as plantas e a fiação elétrica.

Segundo Santos, Lisboa, Carvalho (2012), a arborização viária é primordial para o planejamento urbano por propiciar benefícios socioeconômicos e ambientais que 
proporcionam qualidade de vida adequada, devendo estar inserida nos planos, programas e projetos de gestão urbana, sendo necessário um adequado conhecimento das características e das condições ambientais, uma vez que a relação entre áreas verdes e espaço artificial é dotado de complexidade.

Planejar a arborização é indispensável para o desenvolvimento urbano e requer, antes de qualquer coisa, o conhecimento da situação existente, através de um inventário quali-quantitativo, assim como o conhecimento das características dos vegetais que poderão ser utilizados (COLETTO; MÜLLER; WOLSKI, 2008).

De acordo com Leal, Biondi e Rochadelli (2008), a arborização no contexto urbano é um patrimônio que deve ser mantido e conhecido pela população, assim, torna-se imprescindível à realização de um levantamento florístico dos indivíduos vegetais distribuídos nas vias urbanas, a fim de se planejar a vegetação as condições do entorno.

$\mathrm{Na}$ arborização de cidades brasileiras observa-se uma crescente substituição da flora nativa por plantas exóticas, alterando o ambiente natural que resta nos centros urbanos. Este procedimento uniformiza as paisagens de diferentes cidades e contribui para a redução da biodiversidade no meio urbano, dissociando-o do contexto ambiental onde se insere (MACHADO et al., 2006).

O presente trabalho teve como objetivo quantificar e qualificar as espécies arbóreas presentes no canteiro central da Avenida Deputado Ulisses Guimarães do bairro Promorar na zona sul de Teresina - PI.

\section{METODOLOGIA}

\section{Área de estudo}

A avenida Deputado Ulisses Guimarães localiza-se no bairro Promorar, zona sul de Teresina, capital do Piauí (Figura 1), que está localizada na região Norte do estado, situado no Nordeste do Brasil. A sede do município tem coordenadas geográficas $05^{\circ} 05^{\prime} 12^{\prime \prime}$ de latitude Sul e 4248'42" de longitude Oeste. Possui altitude média de 74,4 m acima do nível médio do mar. O clima de Teresina, pela classificação de Thornthwaite e Mather, configurase como C1s A'a", caracterizado como sub-úmido seco, megatérmico, com excedente hídrico moderado no verão (BASTOS; ANDRADE JÚNIOR, 2008). 

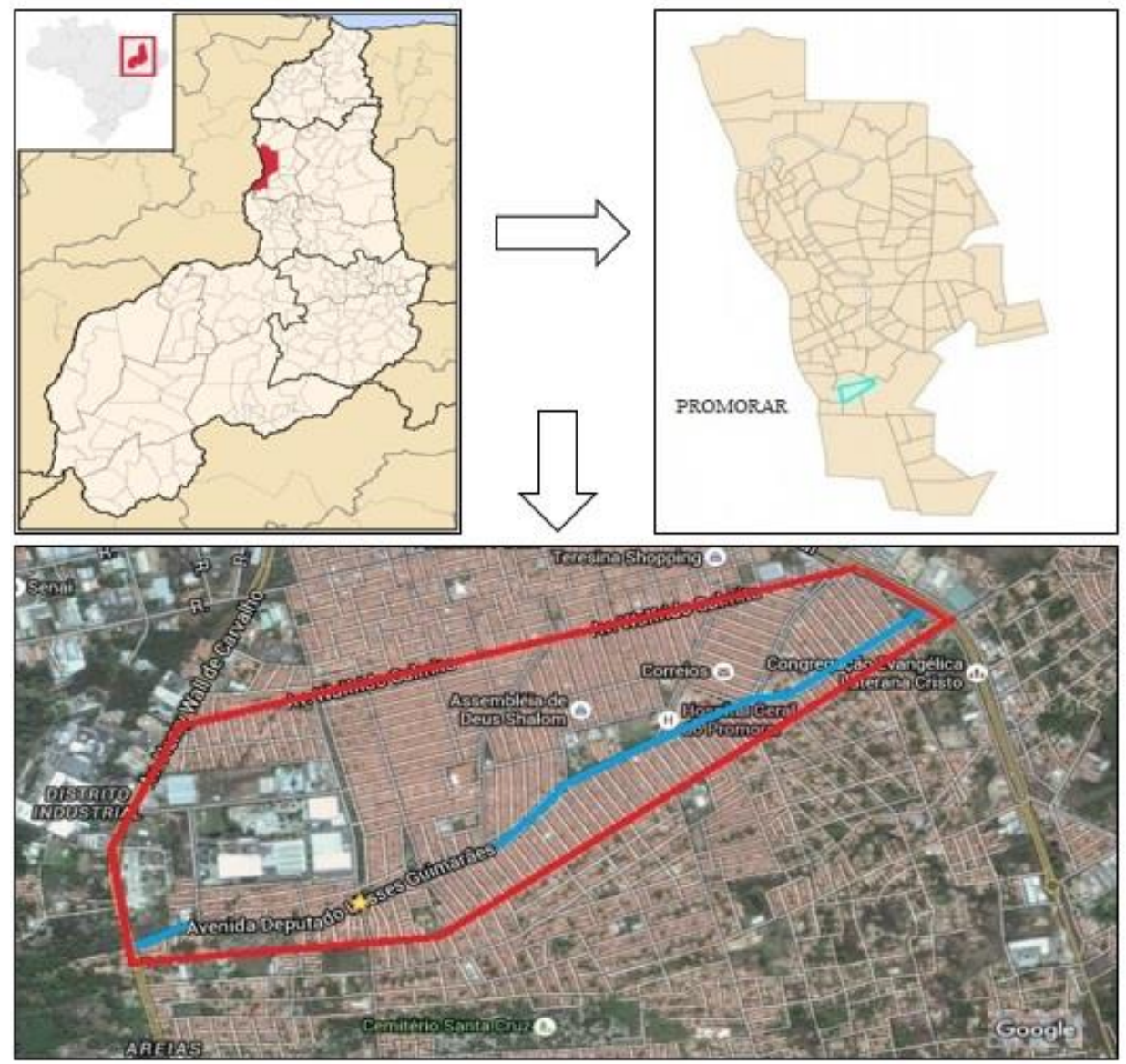

Fonte: Google Earth e Prefeitura de Teresina, adaptado pelos autores. Acessado em 04/12/14

Figura 1. Localização da área de estudo

Figure 1. Location of the study area

No ano de 2012 o canteiro central da Avenida Deputado Ulisses Guimarães passou por uma reforma para a recuperação e implantação de uma galeria, que é o principal sistema de escoamento de água de suas ruas e de vários bairros vizinhos. Por muitos anos o canteiro era utilizado de forma indevida por alguns moradores como depósito de lixo, onde todos os tipos de materiais inutilizáveis (vidro, plásticos, animais mortos entre outros) eram depositados ali, para que posteriormente o sistema de coleta de lixo urbano realizasse a coleta. Esse material indevido causava odores desagradáveis, reduzindo o passeio de transeuntes nesse local, além de atrair vários tipos de animais e aves.

Com a reforma do canteiro central, a avenida ganhou um novo sistema de urbanização, com novas espécies vegetais e construção de passeios nas laterais permitindo a realização de atividades físicas para os moradores. Porém, com a reforma muitos indivíduos arbóreos nativos foram retirados do local, espécies que propiciavam conforto térmico para os transeuntes, devido a sua arquitetura, foram retiradas para a implantação de espécies exóticas, como Azadirachta indica A. Juss. (nim), uma planta exótica que está presente por toda a extensão do canteiro, e que vem ganhando cada vez mais espaço no perímetro urbano de Teresina. Logo, a área de estudo foi escolhida por se tratar de uma via 
de grande movimentação de pedestres em suas passarelas e de veículos, sendo a principal via de acesso presente no bairro.

\section{Coleta de dados}

Foram realizadas análises quantitativas (relacionadas às quantidades de espécies e a quantidade de indivíduos de cada espécie), qualitativas (relacionadas às condições fitossanitárias dos indivíduos, levando em conta o vigor da copa, a integridade do tronco, a existência de injúrias físicas, como lesões e cavidades abertas, o sistema radicular, quando visível, além da presença de pragas e doenças) e o tamanho dos indivíduos. Bem como as condições do canteiro central e a compatibilidade das espécies presentes com o espaço existente, propiciando a elaboração de um diagnóstico da arborização presente nesta área de estudo.

As coletas dos dados foram realizadas de acordo com a metodologia proposta por Salvi et al. (2011) e ocorreram nos meses de setembro e outubro de 2014.

Foram anotadas as seguintes informações: a) número de indivíduos; b) localização do indivíduo, direita ou esquerda do canteiro central, no sentido de leste ao oeste; c) nome comum, d) tamanho do indivíduo (pequeno - até $4 \mathrm{~m}$; médio - entre 4 e $7 \mathrm{~m}$; grande acima de $7 \mathrm{~m}$ ) e e) condições físicas e fitossanitárias aparentes das estruturas vegetais, copa, tronco e raiz quando visível, considerando três categorias: 1 - satisfatória, quando os indivíduos não apresentam danos físicos e/ou fitossanitários, 2 - regular, quando os danos físicos e fitossanitários não são evidentes a olho nu e 3 - ruim, quando a planta apresenta danos físicos e fitossanitários intensos, perceptíveis a olho nu.

A área de crescimento das árvores foi avaliada de forma visual, onde se observou o espaço destinado para plantio das árvores, sendo consideradas três categorias, Satisfatória - quando havia condições para o desenvolvimento do sistema aéreo dos indivíduos, regular quando o espaço para o desenvolvimento era suficiente, porém, causando poucos conflitos com a copa dos outros indivíduos e ruim - quando o espaço destinado para o crescimento era impróprio para o desenvolvimento das plantas. Da mesma forma foi avaliada a área de crescimento das raízes, sendo consideradas três categorias: Satisfatória - quando havia condições para o desenvolvimento do sistema radicular dos indivíduos, regular - quando existia o espaço para o desenvolvimento, porém causando algum conflito com o piso e ruim, quando o espaço destinado para o crescimento radicular era impróprio (observando, se o espaço era pequeno em relação ao porte da árvore).

Os nomes científicos e as famílias de cada espécie foram obtidas das bases de dados Trópicos e The Plant List com o auxílio do sítio PlantMiner (CARVALHO; 
CIANCIARUSO; BATALHA, 2010). Após a identificação dos indivíduos foi verificado a origem dos mesmos.

Os dados foram tabulados em planilha eletrônica do programa Excel, onde foram calculados valores em percentuais para cada variável avaliada.

\section{RESULTADOS E DISCUSSÃO}

Ao longo de toda a extensão do canteiro central da Avenida Deputado Ulisses Guimarães $(2.548 \mathrm{~m})$, observou-se um total de 284 indivíduos arbóreos, pertencentes a 23 espécies, distribuídas em 14 famílias, sendo que destas famílias 52,17\% são nativas da região (Tabela 1 ).

Tabela 1. Espécies encontradas na arborização da Avenida Deputado Ulisses Guimarães, no bairro Promorar, Teresina-PI, 2014

Table 1. Species found in the afforestation of Deputado Ulisses Guimarães Avenue, in the Promorar neighborhood, Teresina-PI, 2014

\begin{tabular}{|c|c|c|c|c|}
\hline Nome Científico & Nome Comum & Família & Origem & Quant. \\
\hline Azadirachta indica A. Juss. & $\mathrm{Nim}$ & Meliaceae & $E$ & 93 \\
\hline Handroanthus chrysotrichus (Mart. ex DC.) Mattos & Ipê-amarelo & Bignoniaceae & $\mathrm{N}$ & 40 \\
\hline Mangifera indica L. & Mangueira & Anacardiaceae & $\mathrm{E}$ & 38 \\
\hline Terminalia catappa L. & Amendoeira & Combretaceae & $E$ & 35 \\
\hline Anacardium occidentale L. & Cajueiro & Anacardiaceae & $\mathrm{N}$ & 11 \\
\hline Schinus terebinthifolius Raddi. & Aroeira & Anacardiaceae & $\mathrm{N}$ & 9 \\
\hline Licania tomentosa (Benth.) Fritsch & Oiti & Chrysobalanaceae & $\mathrm{N}$ & 9 \\
\hline Cenostigma macrophyllum Tul. & Caneleiro & Fabaceae & $\mathrm{N}$ & 9 \\
\hline Spondias mombin & Cajazeira & Anacardiaceae & $E$ & 7 \\
\hline Syzygium cumini (L.) Skeels & Jamelão & Myrtaceae & $E$ & 7 \\
\hline Citrus aurantifolia Swingle & Limão & Rutaceae & $\mathrm{E}$ & 6 \\
\hline Leucaena leucocephala (Lam.) R. de Wit & Leucena & Fabaceae & E & 3 \\
\hline Ficus benjamina L. & Ficus & Moraceae & $E$ & 3 \\
\hline Delonix regia (Bojer ex Hook.) Raf. & Flamboyant & Fabaceae & $E$ & 2 \\
\hline Caesalpinia echinata Lam. & Pau-brasil & Fabaceae & N & 2 \\
\hline Handroanthus roseo-albus (Ridl.) Mattos & Ipê-branco & Bignoniaceae & $\mathrm{N}$ & 2 \\
\hline Anadenanthera macrocarpa (Benth)Brenam & Angico-preto & Fabaceae & $\mathrm{N}$ & 2 \\
\hline Tamarindus indica $\mathrm{L}$. & Tamarindeiro & Fabaceae & E & 1 \\
\hline Paquira aquatica Aubl. & Mamorana & Bombacaceae & $\mathrm{N}$ & 1 \\
\hline Genipa americana L. & Genipapo & Rubiaceae & $\mathrm{N}$ & 1 \\
\hline Caesalpinia sappan & Falso-pau-brasil & Rhamnaceae & $\mathrm{N}$ & 1 \\
\hline Cassia fistula $\mathrm{L}$. & Chuva-de-ouro & Fabaceae & E & 1 \\
\hline Caesalpinia peltophoroides Benth. & Sibipiruna & Fabaceae & $\mathrm{N}$ & 1 \\
\hline
\end{tabular}

Nota: E - Exótica; N - Nativa; Quanti - Quantidade

Hoppen et al. (2014), estudando a arborização de vias públicas da cidade de Farol, $\mathrm{PR}$, observaram que o número de espécies exóticas supera o número de espécies nativas. O mesmo foi reportado por Dall Aqua e Muller (2014) no estudo da arborização em vias de 
Santa Rosa, RS, onde observaram 62\% das espécies como exóticas, opondo-se ao observado neste trabalho.

Segundo a SMAS (2013), deve-se optar na arborização urbana por espécies nativas e espécies típicas da fitogeografia de cada cidade, devido as mesmas contribuírem para o equilíbrio biológico, recuperação e manutenção da fitofisionomia da paisagem. Além disso, a presença de espécies exóticas sobrepondo as nativas em um ambiente pode promover perda da biodiversidade, bem como uma adaptação dessas espécies que passam a ocupar os espaços das espécies nativas (BLUM, 2008; ABENDROTH et al., 2012).

Dentre as espécies mais abundantes na área de pesquisa, destacam-se Azadirachta indica A. Juss. que apresentou um total de 93 indivíduos, seguido por Handroanthus chrysotrichus (Mart. ex DC.) Mattos com 40, Mangifera indica L. com 38 e Terminalia catappa L. com 35 indivíduos, perfazendo um total de 33,00 14, 00, 13,00 e $12,00 \%$ das espécies amostradas. As outras espécies completam a lista com $28 \%$ do total.

Os dados discordam da literatura que recomenda que uma única espécie não deve ultrapassar de $10 \%$ a $15 \%$ do total de espécies em uma área (BIONDI; ALTHAUS, 2005). Porém, concorda com Santamour Júnior et al. (2002) com relação à quantidade de espécies por famílias presente na área de estudo, quando os mesmos sugerem que as espécies de uma mesma família não podem exceder $30 \%$ do total de indivíduos e no presente trabalho foi de $26,08 \%$.

Martini et al. (2014), avaliando a arborização das ruas de um bairro de Curitiba, PR, observaram duas espécies com percentual de indivíduos acima do recomendado, semelhante ao observado neste trabalho.

Observou-se também muitas espécies representadas por poucos indivíduos. Martins et al. (2014) enfatizam que isso pode ser um indicativo de que a arborização tenha sido efetuada sem nenhum tipo de planejamento, de forma aleatória, até mesmo realizada pela população.

Com relação às características de tamanho dos indivíduos, constatou-se que dentre os indivíduos amostrados, 224 apresentavam porte pequeno, 26 com porte médio e $34 \mathrm{com}$ porte grande, $79 \%$, $9 \%$ e $12 \%$ respectivamente do total de indivíduos amostrados.

Como o canteiro central da avenida passou por reformas em 2012/2013, muitas árvores foram retiradas do local, para que a reforma pudesse ser realizada. Dessa forma, as árvores de grande porte sofreram com o processo e foram retiradas da área. Após a reforma do canteiro, novos indivíduos foram plantados, razão pelo qual foi observado o número de indivíduos de pequeno porte se destacando em relação aos demais.

Outro aspecto que merece destaque é que aproximadamente $30 \%$ das espécies observadas são frutíferas. Segundo Barros; Guilherme; Carvalho, (2010), essa característica pode acarretar problemas, tendo em vista que árvores de médio e grande porte que 
possuem frutos volumosos podem apresentar perigo de queda em veículos, edificações e principalmente em transeuntes.

Para as condições fitossanitárias, os indivíduos receberam classificação satisfatória, ou seja, os indivíduos não possuem problemas fitossanitários tanto na copa, quanto no tronco e na raiz, sendo o percentual de $71,67 \%, 93,33 \%$ e $95,00 \%$ respectivamente do total, permitindo calcular um valor médio para estas características de $86,83 \%$ (Tabela 2).

Tabela 2. Condições fitossanitárias, área de crescimento das raízes e localização das árvores avaliadas na Avenida Deputado Ulisses Guimarães no bairro Promorar, Teresina-PI, 2014

Table 2. Phytosanitary conditions, growth area of the roots and location of the trees evaluated in the Deputado Ulisses Guimarães Avenue in the Promorar neighborhood, Teresina-PI, 2014

\begin{tabular}{|c|c|c|c|c|c|c|c|c|}
\hline \multicolumn{5}{|c|}{ Condições Fitossanitárias } & \multicolumn{2}{|c|}{$\begin{array}{l}\text { Área de Crescimento } \\
\text { das raízes \% }\end{array}$} & \multicolumn{2}{|c|}{ Localização } \\
\hline & Copa & Tronco & Raiz & Médias & & & & \\
\hline Satisfatória & 71.67 & 93.33 & 95.00 & 86.63 & Satisfatória & 93.33 & Esquerda & 16.67 \\
\hline Regular & 25.00 & 5.00 & 3.33 & 11.15 & Regular & 1.67 & Direita & 25.00 \\
\hline Ruim & 3.33 & 1.67 & 1.67 & 3.22 & Ruim & 5.00 & Centro & 58.33 \\
\hline
\end{tabular}

Estes resultados são semelhantes aos observados por Coletto, Muller e Wolski (2008), que fazendo um diagnóstico da arborização das vias públicas do município de sete de setembro - RS, relataram que $86,4 \%$ dos indivíduos amostrados obtiveram classificações fitossanitárias similares. Porém, os dados discordam dos reportados por Andreatta et al., (2011) que fazendo uma análise da arborização no contexto urbano de avenidas de Santa Maria - RS, relataram que apenas $38 \%$ dos indivíduos amostrados obtiveram esta classificação para as características fitossanitárias.

Quanto à área de crescimento das raízes, 93,33\% dos indivíduos apresentaram classificação satisfatória, ou seja, condições para o pleno desenvolvimento do sistema radicular das árvores. Pelo fato de ter ocorrido à reforma do canteiro central da Avenida Deputado Ulisses Guimarães, novas árvores foram plantadas, algumas foram transferidas de local e outras permaneceram no local original, de forma a não trazer prejuízos para os transeuntes e nem para as plantas. Esse percentual de indivíduos com ótima área de crescimento foi superior ao observado por Andreatta et al., (2011), que relataram que dos indivíduos amostrados apenas $16 \%$ apresentaram problemas de incompatibilidade com o local em que as plantas se encontravam. Observou-se ainda que, 100\% dos indivíduos avaliados apresentaram classificação satisfatórias para área de crescimento da parte aérea, não apresentando quaisquer conflitos com fiações e postes.

Com relação à localização, observou-se que os indivíduos estavam dispostos em diferentes locais ao longo do canteiro central. 58,33\% dos indivíduos estavam localizados no centro (Figura 2-A) e $41,67 \%$ nas laterais (Figura $2-B$ ) sendo $25,00 \%$ no lado direito e 
16,67 no lado esquerdo. Observou-se ainda um pequeno número de indivíduos (5 árvores) localizado dentro do passeio (Figura 2-C).

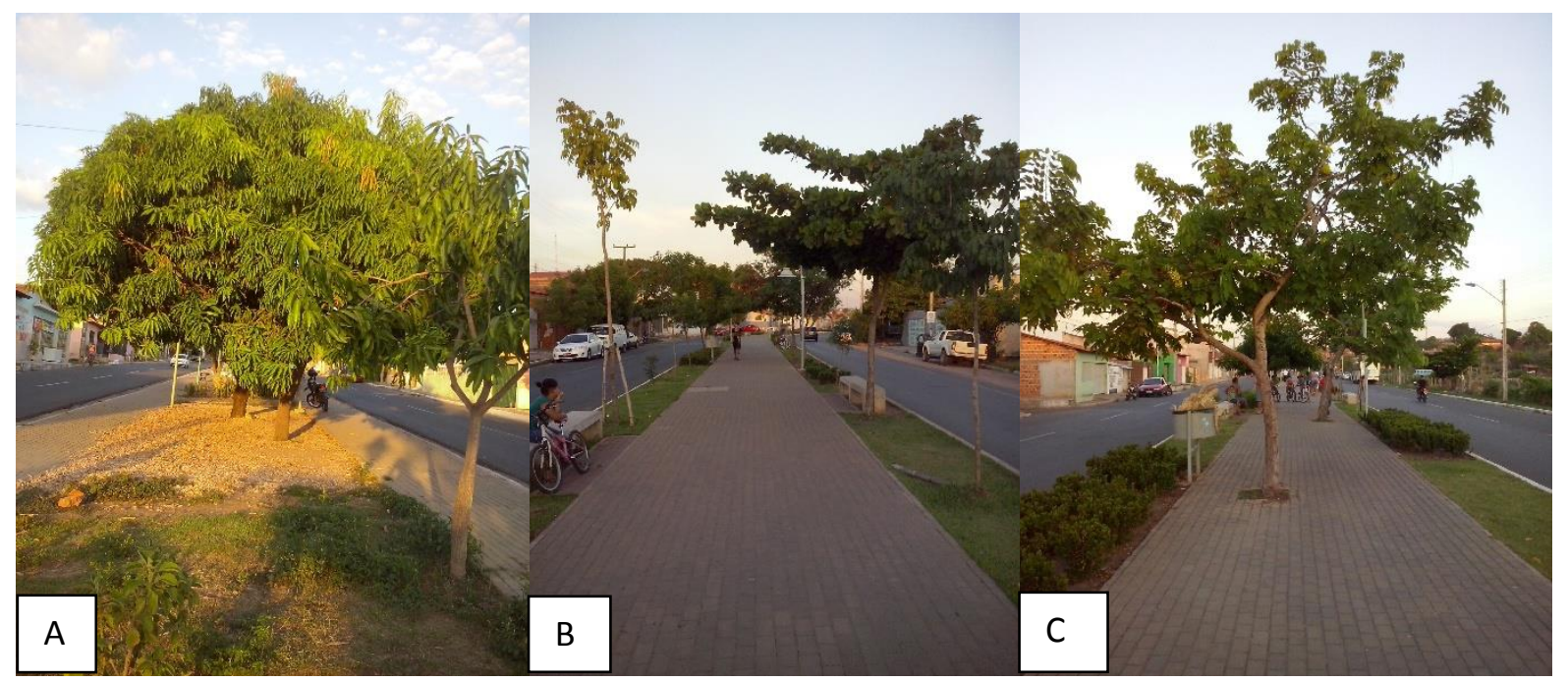

Figura 2 Localização das plantas no centro (A), nas laterais (B) e dentro do passeio (C) do canteiro central da Avenida Deputado Ulisses Guimarães no Bairro Promorar, Teresina - PI, 2014

Figure 2. Location of the plants in the center $(A)$, the side $(B)$ in the sidewalk $(C)$ on the median strip in Deputado Ulisses Guimarães Avenue in the Promorar neighborhood, Teresina - PI, 2014

Em grande parte da extensão do canteiro central $(1.665,00 \mathrm{~m})$, os passeios localizam-se nas bordas, sendo a área de plantio das árvores localizada na parte central do canteiro. Em outra extensão do mesmo (883 m), as árvores estão dispostas nas bordas do canteiro e a área de passeio localiza-se no centro. Isso justifica a maior quantidade de indivíduos localizados nas laterais do canteiro.

Os indivíduos localizados na área do passeio são justificados por se tratar de árvores que se encontravam no local há muitos anos e não proporcionariam problemas para o andamento da reforma do canteiro, contribuindo para a memória florística da área. Isso mostra que houve conscientização dos responsáveis pela reforma, em não excluir do canteiro espécies arbóreas, que possuem importância histórica, ambiental e de conforto térmico, além da estética da área. No entanto, além de haver a alteração do traçado da calçada para manter as árvores, o espaço destinado ao crescimento de algumas árvores, principalmente as que estavam no centro do canteiro, são pequenos em relação ao porte das árvores, tornando-se inviável a permanência desses indivíduos que poderão futuramente causar conflitos com a calçada. 


\section{CONCLUSÃO}

A arborização da Avenida Deputado Ulisses Guimarães, apresenta uma boa relação de quantidade de famílias por área, apresenta um grande número de indivíduos da mesma espécie por área.

As espécies nativas apresentaram maior ocorrência na avenida, visto de forma positiva. Por outro lado, deve-se levar em consideração o percentual de espécies exóticas, que, apesar de estarem em número menor, podem suprimir as espécies nativas futuramente.

A arborização apresenta condições fitossanitárias e área de crescimento tanto para parte aérea quanto para sistema radicular em níveis satisfatórios, devendo-se atentar para os conflitos com a estrutura física do canteiro, embora o percentual de conflito tenha sido baixo.

Destaca-se a presença de árvores frutíferas, necessitando-se de cuidados principalmente em períodos de frutificação.

Embora a arborização da Avenida Deputado Ulisses Guimarães não tenha saído totalmente dos padrões de um plano de arborização, recomenda-se que a arborização siga um planejamento de acordo com as orientações sugeridas pela literatura especializada.

\section{REFERÊNCIAS}

ABENDROTH, A.; KOWARIK. I.; MULLER. N.; LIPPE. M. The green colonial heritage:woody plants in park of Bandung, Indonesia. Landscape and Urban Planning, Amsterdam, v.106, n.1, p.12-22, 2012.

ANDREATTA, T. R.; BACKES, F. A. A. L.; BELLÉ, R. A.; NEUHAUS, M.; GIRARDI, L. B.; SCHWAB, N. T.; BRANDÃO, B. S. Análise da arborização no contexto urbano de avenidas de Santa Maria - RS. Revista da Sociedade Brasileira de Arborização Urbana, Piracicaba, v. 6, n.1, p. 36-50, 2011.

BARROS, E. F. S.; GUILHERME, F. A. G.; CARVALHO, R. S. Arborização urbana em quadras de diferentes padrões construtivos na cidade de Jataí. Revista Árvore, Viçosa, v. 34 , n. 2, p. 287-295, 2010.

BASSO, J. M.; CORRÊA, R. S. Arborização urbana e qualificação da paisagem. Paisagem e Ambiente, São Paulo, v.1 n. 34, p. 129-148, 2014.

BASTOS, A. E.; ANDRADE JÚNIOR, A. S. de. Boletim agrometeorológico de 2007 para o Município de Teresina, PI. Embrapa Meio-Norte. Documentos, 132. Teresina, 2008.

BIONDI, D.; ALTHAUS, M. Árvores de rua de Curitiba: cultivo e manejo. Curitiba: FUPEF, 2005. 177p. 
BLUM, C.T. Espécies exóticas invasoras na arborização de vias públicas de Maringá-PR. Revista da sociedade brasileira de arborização urbana, Piracicaba, v. 3, n. 2, p.78- 97, 2008.

CARVALHO, G. H.; CIANCIARUSO, M. V.; BATALHA, M. A. Plantminer: a web tool for gathering plant species taxonomic information. Environmental Modelling \& Software, Amsterdam, v. 25, p. 815-816, 2010.

COLETTO, E. P; MULLER, N. G; WOLSKI, S. S. Diagnóstico da arborização das vias públicas do município de Sete de Setembro - RS, Revista da Sociedade Brasileira de Arborização Urbana, Piracicaba, v. 3, n. 2, p. 110-128, 2008.

CRUZ, D. C. A.; BEVILAQUA, L. C.; ARRUDA, G. O. S. F. Diagnóstico da arborização da Avenida Plínio Arlindo de Nês, município de Xanxim, SC. Unoesc e ciência, Joaçaba, v. 3, n.2, p. 147-156, 2012.

DALL AQUA, M.; MULLER, N. T. G. Diagnóstico da arborização urbana de duas vias na cidade de Santa Rosa - RS. Revista da sociedade brasileira de arborização urbana, Piracicaba, v. 9, n. 3, p. 141-155, 2014.

HOPPEN, M. I.; DIVENSI, H. F.; RIBEIRO, R. F.; CAXAMBÚ, M. G. Espécies exóticas na arborização de vias públicas no município de Farol-PR, Brasil. Revista da Sociedade Brasileira de Arborização Urbana, Piracicaba, v. 9, n. 3, p.173-186, 2014.

KRAMER, J. A.; KRUPEK, R. A. caracterização florística e ecológica da arborização de praças públicas do município de Guarapuava, PR. Revista Árvore, Viçosa, v. 36, n. 4, p. 647-658, 2012.

LEAL, L.; BIONDI, D.; ROCHADELLI, R. Custos de implantação e manutenção da arborização de ruas da cidade de Curitiba, PR. Revista Árvore, Viçosa, v. 32, n. 3, p. 557565, 2008.

LONDE, P. R.; MENDES, P. C. A influência das áreas verdes na qualidade de vida urbana. Hygeia, Uberlândia, v. 10, n. 18, p. 264-272, 2014.

MACHADO, R. R. B.; MEUNIER, I. M. J.; SILVA, J. A. A.; CASTRO, A. A. J. F. Árvores nativas para a arborização de Teresina, Piauí. Revista da Sociedade Brasileira de Arborização Urbana, Piracicaba, v. 1, n. 1, p. 10-18, 2006.

MARTINI, A.; GASPAR, R. G. B.; BIONDI, D. Diagnóstico da implantação da arborização de ruas do bairro Santa Quitéria, Curitiba. Revista da Sociedade Brasileira de Arborização Urbana, Piracicaba, v. 9, n. 2, p. 148-167 2014.

MARTINS, L.C.; NUNES, A. L.; NUNES, A. M.; BRAGA, H. S. Análise comparativa da arborização urbana de três cidades da região do alto São Francisco/ Minas Gerais. Revista Agrogeoambiental, Pouso Alegre, v. 6 n. 2, p. 31-42,2014.

OLIVEIRA, A. S.; SANCHES, L.; DE MUSIS, C. R. Benefícios da arborização em praças urbanas - o caso de Cuiabá/MT. Revista Eletrônica em Gestão, Educação e Tecnologia Ambiental, Santa Maria, v. 9, n. 9, p. 1900-1915, 2013.

SALVI, L. T.; HARDT, L. P. A.; ROVEDDER, C. E.; FONTANA, C. S. Arborização ao longo de ruas, túneis verdes em Porto Alegre, RS, Brasil: avaliação quantitativa e qualitativa. Revista Árvore, Viçosa, v.35, n. 2, p. 233-243, 2011. 
SANTAMOUR JÚNIOR, F. S. Trees for urban planting: diversity uniformity, and common sense. Agriculture Research Service, Washington, v. 7, p. 57-65, 2002.

SANTOS, T. O. B.; LISBOA, C. M. C. A.; CARVALHO, F. G. Análise da arborização viária do bairro de Petrópolis, Natal, RN: uma abordagem para diagnóstico e planejamento da flora urbana. Revista da Sociedade Brasileira de Arborização Urbana, Piracicaba, v.7, n.4, p.90-106, 2012.

SECRETARIA DE MEIO AMBIENTE E SUSTENTABILIDADE - SMAS. Manual de arborização: orientações e procedimentos técnicos básicos para a implantação e manutenção da arborização da cidade do Recife.1. ed. - Recife: [s.n.], 2013. 71 p.

SILVA, A.T.; TAVARES, T.S.; PAIVA, P.D.O.; NOGUEIRA, D.A. As praças Dr. Augusto Silva e Leonardo Venerando Pereira, Lavras - MG, segundo a visão dos seus frequentadores. Ciência e Agrotecnologia, Lavras, v. 32, n. 6, p.1701-1707, 2008. 